\title{
Alphitobius diaperinus como veiculador de Clostridium perfringens em granjas avícolas do interior paulista-Brasil
}

\author{
Alphitobius diaperinus as a vector of Clostridium perfringens in broiler houses in the state of \\ São Paulo - Brazil
}

\author{
Juliano Vittori ${ }^{1}$ Rubén Pablo Schocken-Iturrino $^{I^{*}}$ Kátia Prochnon Trovó $^{1}$ \\ César Augusto Martins Ribeiro" ${ }^{\mathrm{II}}$ Gislaine Gomes Barbosa ${ }^{\mathrm{I}}$ \\ Luciano Melo de Souza ${ }^{\text {II }}$ Caroline Peters Pigatto ${ }^{\text {II }}$
}

\begin{abstract}
O besouro Alphitobius diaperinus (cascudinho) é visto como uma importante praga da avicultura mundial. Por suas características comportamentais e hábitos biológicos que dificultam seu controle, é considerado um vetor de agentes patogênicos. O objetivo desta pesquisa foi investigar o cascudinho como possível vetor de Clostridium perfringens em granjas avícolas industriais, localizadas em diferentes regiões do interior Paulista. Através de métodos bacteriológicos convencionais, em 40 amostras analisadas, foram encontradas contagens significativas de Clostridium perfringens em todas elas. A partir dos resultados obtidos, pôde-se demonstrar o potencial deste inseto como vetor do agente responsável pela enterite necrótica.
\end{abstract}

Palavras-chave: avicultura, Clostridium perfringens, cascudinho, enterite necrótica.

\section{ABSTRACT}

The Alphitobius diaperinus (lesser mealworm) is considered an important world poultry plague. Due to its behavior characteristics and biological habits that make its control difficult it is considered a vector of pathogenic agents. The objective of this research was to investigate the little mealworm as possible vector of Clostridium perfringens in broiler houses, located in different parts of the state of São Paulo. Through conventional bacteriological methods, 40 samples of little mealworm collected were analyzed. Clostridium perfringens was found in all of the samples and the potential of this insect as vector of the necrotic enteritis was demonstrated.

Key words: poultry brooder houses, Clostridium perfringens, lesser mealworm, necrotic enteritis.
A avicultura é um dos setores agropecuários que mais tem crescido nas últimas décadas. Os frangos de corte oriundos de granjas são abatidos cada vez mais precocemente, sendo criados de maneira intensiva e submetidos a vários fatores de estresse como: vacinações, transporte, superlotação de galpões, excesso de frio e/ou calor, bem como a presença de insetos (AVISITE, 2004).

O besouro Alphitobius diaperinus (Coleoptera: Tenebrionidae), conhecido como “cascudinho”, é encontrado em grande quantidade em cama de frango. A criação em confinamento proporcionou ao cascudinho um hábitat ideal para a sua multiplicação, transformando-o num problema mundial. As formas larval e adulta são descritas como mantenedoras de patógenos viáveis na sua superfície externa e no seu trato digestivo (PAIVA, 2000).

Por suas características comportamentais e hábitos biológicos que dificultam seu controle e o caracterizam como "transportador e disseminador" de patógenos, o cascudinho passou a ser considerado importante agente causador de prejuízos econômicos e sanitários na produção avícola (BATES et al., 2004). Dentre os patógenos que podem ser veiculados pelo cascudinho, ressalta-se Clostridium perfringens.

Clostridium perfringens é uma bactéria em forma de bastonete, Gram positivo, anaeróbia, com esporos subterminais e centrais (SCHOCKENITURRINO \& ISHI, 2000). Produz vários tipos de toxinas, mas é classificada de Aa E, em razão das toxinas

IDepartamento de Microbiologia, Universidade Estadual Paulista (UNESP). Via de acesso Prof. Paulo Donato Castellane, s/n, Zona

Rural, 14870-970, Jaboticabal, SP, Brasil. E-mail: pablo@fcav.unesp.br.*Autor para correspondência.

IIDepartamento Medicina Veterinária Preventiva, UNESP, Jaboticabal, SP, Brasil 
alfa, beta, epsilon, teta, iota, kappa, lambda e mú, capazes de provocar patologias diversas, principalmente a enterite necrótica (CARTER, 1998). Esta doença é uma enterotoxemia aguda nãocontagiosa, com início súbito, e apresenta necrose confluente do intestino delgado, que, em infecções subclínicas, provoca redução na absorção dos nutrientes e, conseqüentemente, menor ganho de peso e piora na conversão alimentar. A enterite necrótica é encontrada principalmente em animais jovens, sendo causada pelos tipos A e C de Clostridiun perfrigens (SCHOCKEN-ITURRINO \& ISHI, 2000). O objetivo desta pesquisa foi investigar o potencial do besouro Alphitobius diaperinus como vetor de Clostridium perfringens em granjas avícolas industriais, localizadas em diferentes regiões do interior paulista.

Foram obtidas 40 amostras de Alphitobius diaperinus, no período de agosto de 2005 a fevereiro de 2006. Destas, 50\% foram colhidas em galpões avícolas localizados na região de Sertãozinho (SP), e o restante foi proveniente de galpões situados na região de Descalvado (SP).

Cada amostra era constituída de aproximadamente 700 besouros adultos, pesando cerca de $10 \mathrm{~g}$. Para tal, os insetos eram coletados em pontos aleatórios dos galpões, sendo posteriormente acondicionados em recipiente de vidro estéril, fechado e transportado em caixa de isopor até o laboratório para as análises. Após pesagem dos besouros, esses foram triturados com areia estéril em um cadinho de porcelana e diluídos em $90 \mathrm{~mL}$ de peptona $0,1 \%$ previamente esterilizada. Esta solução foi submetida à homogeneização por três minutos manualmente e feitas diluições seriadas até $10^{-3}$. Alíquotas de $1 \mathrm{~mL}$ das diluições foram semeadas, em duplicata, pelo método "pour plate" em placas de petri com adição do meio agar sulfito-polimixina-sulfodiazina (SPS-Oxoid), previamente esterilizado e fundido. O material foi incubado em condições de anaerobiose utilizando jarras com sistema Gas-Pak, à temperatura de $37^{\circ} \mathrm{C}$, por $24-48$ horas (SPECK, 1992). Para confirmar a pureza das colônias típicas, estas foram repicadas em placas contendo meio SPS e incubadas nas mesmas condições citadas anteriormente (SCHOCKEN-ITURRINO et al., 1988). Os esfregaços destas colônias foram corados pelo método de Gram para observação microscópica. Para identificação, cinco colônias típicas de cada placa eram submetidas à série bioquímica a partir das colônias de bastonetes Gram-positivos esporulados e catalase negativa, sendo estas repicadas em tubos de infusão de cérebro e coração (BHI- Difco), incubados em anaerobiose, a $37^{\circ} \mathrm{C}$, por 24 horas (SCHOCKENITURRINO et al., 1988). Os testes bioquímicos realizados foram: prova da gelatinase, motilidade, fermentação de lactose, maltose, sacarose, salicina, produção de indol, nitrato e $\mathrm{H}_{2} \mathrm{~S}$ (CARTER et al., 1995).
Para a análise estatística, foi utilizado um delineamento inteiramente casualizado, sendo composto por dois tratamentos, com 20 repetições cada. Os dados das contagens microbianas foram transformados em $\log _{10}$, sendo submetidos à análise de variância e as médias comparadas pelo Teste de Tukey, ao nível de 5\% de probabilidade.

Clostridium perfringens foram isolados em todas as 40 amostras de Alphitobius diaperinus analisadas. Este dado revela a importância do controle dos cascudinhos para evitar a disseminação da enterite necrótica causadora de grandes prejuízos econômicos. Após ampla revisão de literatura, não foram encontrados relatos de isolamento de Clostridium perfringens em amostras envolvendo o agente Alphitobius diaperinus no mundo. Por isso, a caracterização desse inseto como veiculador desta bactéria torna este estudo relevante para a avicultura brasileira. Na Tabela 1, nota-se que não houve diferença significativa $(\mathrm{P}>0,05)$ nas contagens de Clostridium perfringens em Alphitobius diaperinus nas diferentes regiões estudadas. As médias para as contagens em UFC/g variaram de $2 \times 10^{1}$ a l, $12 \times 10^{3} \mathrm{em}$ Descalvado e 9 x $10^{1}$ a $9,4 \times 10^{3}$ nas amostras de Sertãozinho.

A participação do Alphitobius diaperinus como vetor de agentes patogênicos foi comprovada nos relatos de HOFSTAD et al. (1972), SAFRIT \& AXTELL(1984), BALDASSI et al.(1995), PAIVA(2000), GOMES (2000), WATSON et al. (2003) e SKOV et al. (2004), que isolaram Eimeria, Escherichia, Salmonella, Campylobacter, Bacillus, Streptococcus, Aspergillus, vírus causadores das doenças de Marek, Influenza aviária, Gumboro e Newcastle, reovírus, rotavírus e enterovírus em diferentes partes do mundo. É considerado também vetor da leucose aviária (DESPINS \&AXTELL, 1995). JENSEN et al. (2006), em investigações realizadas em granjas da Dinamarca, estabeleceram a correlação entre a presença de Salmonella typhimurium e de Alphitobius diaperinus, observando-se que a eliminação da bactéria nos plantéis somente foi possível quando ocorreu a eliminação do coleóptero. No mesmo país, HALD et al. (1998), isolaram Salmonella enterica sorovar Infantis em $45 \%$ dos cascudinhos amostrados no período em que a granja estava vazia, ou seja, no intervalo entre a saída e chegada de lotes. Desta forma, o inseto contaminará o novo lote de aves.

No Brasil, CHERNAKI-LEFFER et al. (2002) encontraram Proteus vulgaris, P. mirabilis, Escherichia coli, Enterobacter spp., Enterobacter agglomerans, Enterobacter gergoviae, Enterobacter sakasakii, Citrobacter diversus e Klebsiella pneumoniae, causadores de diversas patologias em aves em cascudinhos da região oeste do Estado do Paraná. Trabalho semelhante foi realizado em granjas de perus e frangos nos Estados de Santa Catarina e 
Tabela 1 - Médias das contagens de Clostridium perfringens ( $\log { }_{10}$ ), de amostras de Alphitobius diaperinus colhidas em 2 regiões avícolas no período de agosto/2005 a fevereiro/2006.

\begin{tabular}{lccc}
\hline Granjas avícolas & Clostridium perfringens $\left(\log _{10}\right)$ & Coeficiente de variação & DMS* \\
\hline Sertãozinho & $3,223 \mathrm{a}$ & $24,90 \%$ & 0,497 \\
Descalvado & $3,019 \mathrm{a}$ & & \multirow{2}{*}{ a } \\
\hline
\end{tabular}

Médias seguidas de mesmas letras não diferem $(\mathrm{P}>0,05)$ pelo Teste de Tukey.

* Desvio médio significativo.

Rio Grande do Sul, onde foram encontrados 14 espécies de dez gêneros de bactérias da família Enterobacteriaceae (SEGABINAZI et al.,2005). A presença destas enterobactérias nos cascudinhos demonstra o grande potencial deste inseto em albergar bactérias patogênicas para as aves também em nosso país.

A partir dos resultados obtidos, demonstrou-se o potencial do Alphitobius diaperinus como vetor do Clostridium perfringens em granjas avícolas. O combate deste agente, através de controle químico ou biológico, bem como de um manejo higiênico sanitário adequado dos animais e do ambiente, é fundamental, em vista que essa praga pode carrear agentes patogênicos com potencial de causar danos econômicos na criação avícola.

\section{AGRADECIMENTO}

Ao Conselho Nacional de Desenvolvimento Científico e Tecnológico (CNPq), pela concessão de bolsa de estudo.

\section{REFERÊNCIAS}

AVISITE. Estatísticas e preços de carne de frango. Capturado em 20 de out. 2004. Online. Disponível na Internet: http://www.avisite.com.br/noticias/default.asp.

BALDASSI, L. Necrotic enteritis on broilers in São Paulo State. Arquivos do Instituto Biológico, São Paulo, v.62, n.1/2, p.3743, 1995.

BATES, C. at al. Relationship of Campylobacter isolated from poultry and from darkling beetles in New Zealand. Avian Diseases, Washington, v.48, p.138-147, 2004.

CARTER, G.R. et al. Essencialts of veterinary microbiology. 5.ed. London: Willians \& Wilkins, 1995. 394p.

CARTER, G.R. Fundamentos de bacteriologia e micologia veterinária. 3.ed. São Paulo: Roca, 1998. 249p.

CHERNAKI-LEFFER,A.M. et al. Isolamento de Enterobacérias em Alphitobius diaperinus e na Cama de Aviários no oeste do Estado do Paraná, Brasil. Revista Brasileira de Ciência Avícola, Campinas, v.4, p.243-247, 2002.

DESPINS, J.L; AXTELL, R.C. Feeding behavior and growth of broiler chicks fed larvae of the darkling beetle, Alphitobius diaperinus. Poultry Science, Savoy, v.74, p.331-336, 1995. GOMES, J.P.C. Controle de Alphitobius diaperinus (Panzer) (Coleoptera: Tenebrionidae) em aviários. In: SIMPÓSIO BRASIL SUL DE AVICULTURA, 2000, Chapecó- SC. Anais... Chapecó: Núcleo Oeste de Médicos Veterinários, 2000. p.143147.

HALD, B. et al. Typhaea stercorea (Coleoptera: Mycetophagidae), a Carrier of Salmonella enterica serovar Infantis in a Danish Broiler House. Veterinary Entomology, Whashington, v.91, n.3, p.660-664, 1998.

HOFSTAD, M. et al. In: CALNECK, B.W. et al. Diseases of Poultry. 7.ed. Ames: Iowa State Univ., 1972. 365p.

JENSEN, A.N. et al. Survival and transmission of Salmonella enterica Serovar Typhimurium in an outdoor organic pig farming environment. Applied and Environmental Microbiology, Quebec, v.72, n.3, p.1833-1842, 2006.

PAIVA, D.P. Cascudinhos: biologia. In: SIMPÓSIO BRASIL SUL DE AVICULTURA, 2000, Chapecó-SC. Anais... Chapecó: Núcleo Oeste de Médicos Veterinários, 2000. p.135139 .

SAFRIT, R.D.; AXTELL, R.C. Evaluations of sampling methods for darkling bettles (Alphitobius diaperinus) in the little of turkey and broiler houses. Poultry Science, Savoy, v.63, p.2368-2375, 1984.

SCHOCKEN-ITURRINO, R.P. et al. Isolation and characterization of pathogenic Clostridium in meat products. Ars Veterinaria, Jaboticabal, v.4, n.1, p.91-98, 1988.

SCHOCKEN-ITURRINO, R.P; ISHI, M. Clostridioses em aves. In: BERCHIERI Jr, A., MACARI, M. Doenças das aves. Campinas: Facta, 2000. p.242-243.

SEGABINAZI,S. D. et al. Bactérias da família Enterobacteriaceae em Alphitobius diaperinus oriundos de granjas avícolas dos Estados do Rio Grande do Sul e Santa Catarina, Brasil. Acta Scientiae Veterinariae, Porto Alegre, v.33, n.1, p.51-55, 2005.

SKOV, M.N. et al. The role of litter beetles as potential reservoir for Salmonella enterica and Thermophilic Campylobacter spp. between broiler flocks. Avian Diseases, Whashington, v.48, p.9-18, 2004.

SPECK, M.L. Compendium of methods for the microbiological examination of foods. Washington: APHA, 1992. 701p.

WATSON, D.W. et al. Effects of lime hydrate on the growth and development on darkling beetle, Alphitobius diaperinus. International Journal of Poultry Science, Whashington, v.2, n.2, p.91-96, 2003. 